\title{
Re-use assessment of thermoset composite wastes as aggregate and filler replacement for concrete-polymer composite materials: A case study regarding GFRP pultrusion wastes
}

\author{
M.C.S. Ribeiro, A.C. Meira-Castro, F.G. Silva, J. Santos, \\ J.P. Meixedo, A. Fiúza, M.L. Dinis, M.R. Alvim
}

\begin{abstract}
Glass fibre-reinforced plastics (GFRP), nowadays commonly used in the construction, transportation and automobile sectors, have been considered inherently difficult to recycle due to both the cross-linked nature of thermoset resins, which cannot be remoulded, and the complex composition of the compos- ite itself, which includes glass fibres, polymer matrix and different types of inorganic fillers. Hence, to date, most of the thermoset based GFRP waste is being incinerated or landfilled leading to negative envi- ronmental impacts and additional costs to producers and suppliers. With an increasing awareness of environmental matters and the subsequent desire to save resources, recycling would convert an expen- sive waste disposal into a profitable reusable material. In this study, the effect of the incorporation of mechanically recycled GFRP pultrusion wastes on flexural and compressive behaviour of polyester poly- mer mortars (PM) was assessed. For this purpose, different contents of GFRP recyclates $(0 \%, 4 \%, 8 \%$ and $12 \%$, $\mathrm{w} / \mathrm{w}$ ), with distinct size grades (coarse fibrous mixture and fine powdered mixture), were incorpo- rated into polyester PM as sand aggregates and filler replacements. The effect of the incorporation of a silane coupling agent was also assessed. Experimental results revealed that GFRP waste filled polymer mortars show improved mechanical behaviour over unmodified polyester based mortars, thus indicating the feasibility of GFRP waste reuse as raw material in concrete-polymer composites.
\end{abstract}

\section{Keywords}

Glass fibre reinforced polymers, Thermoset composite wastes, Mechanical recycling, Polymer concrete materials, Mechanical behavior, Nonparametric factorial data analysis.

\section{Introduction}

Worldwide volume production and consumption of fibre reinforced polymers (FRP) have increased in the last decades in several fields, mostly in the construction, automobile and aeronautic sectors (Broekel and Scharr, 2005; Karbhari, 1998; Sims, 2001). The high strength to weight ratio, corrosion resistance and design flexibility make FRP based materials an interesting alternative to steel and other similar materials. Despite all the advantages of FRP based products, the increasing production and consumption also drives to an increasing amount of FRP wastes, either as end-of-life products or as manufacturing rejects. According to a recent market report of LUCINTEL, 2012, a leading global management market research firm, just the global glass fibre market is expected to reach an estimated $\$ 11.2$ billion in 2017 with a Compound annual growth rate (CAGR) of $6.9 \%$ over the five years-period 2012-2017. Accordingly, the FRP composite industry will contribute with its share to this scenario, and this trend of increasing production will lead, thereby, to increasing manufacturing wastes and, in the near future, tolarger amounts of end-of-life products. Thus, the recyclability of this type of scrap material has become an important and concerning issue. Whereas thermoplastic FRPs can be easily recycled by remelting and remoulding, recyclability of thermosetting FRPs is a more difficult task due to the cross-linked nature of resin matrix (Pimenta and Pinho, 2011). Hence, presently, most of the thermoset based FRP waste is still being incinerated or landfilled, leading to negative environmental impacts and additional costs to FRP producers and suppliers.

Taking into account the actual and impending framework on waste management legislation (e.g., EU 1999/31/EC; EU 2000/53/EC; EU 2000/76/EC; EU 2006/12/EC), as well as the predicted increase of landfill taxes and limited capacity, landfill and incineration will no longer be acceptable solutions. In Portugal, 
the average landfill tipping fee in 2010 was about 26 D per tonne (Marques et al., 2012); and this figure is estimated to rise up to 120 D for composite material wastes at the end of this year. On the other hand, it is expected that the incineration tax will be set-up similar to the landfill tax in order to encourage re-use and recycling of waste where possible before landfill and incineration (Halliwell, 2006). Hence, the FRP manufacturers and suppliers are facing the risk of losing their market share to metals and other industries if they cannot ensure that their FRP components can be reused or recycled at the end of their life (Conroy et al., 2006; Pickering, 2006; Villanueva et al., 2010). At the present time, in order to ensure the development or even continued use of these materials in some markets, the optimization of recycling processes and the development of further cost-effective end-use applications for the recyclates are required.

Under this scope, this study is aimed at developing a new waste management solution for GFRP (glass fibre reinforced polymer) waste recyclates in order to meet the main criteria for costeffectiveness. For this purpose, different contents and size grades of mechanically recycled GFRP waste were incorporated into polyester polymer mortars (PM) as sand aggregates and filler replacements. Added value of the recycling solution was assessed by means of flexural and compressive load carrying capacities of GFRP admixed mortars with regard to unmodified PMs. The plan-

ning of experiments and data treatment were accomplished by means of full factorial design and through appropriate statistical tools based on analyses of variance, which over the last years have shown to be powerful tools in the optimization processes of mixtures, mix designs and processing parameters (Correia et al., 2009, 2010; Muthukumar and Mohan, 2004; Ribeiro et al., 2003b).

In Section "Literature review on end-use applications for GFRP waste recyclates", a review of the state of the art on end-use applications for mechanically recycled GFRP wastes is given and endorses the present experimental work described in Sections "Experimental programme", "Results", "Discussion" and "Conclusions".

\section{Literature review on end-use applications for GFRP waste recyclates}

At present, there are basically three main recycling methods for FRP thermostable materials: (a) incineration, with partial energy recovery due to the heatgenerated during organic partcombustion; (b) thermal and/or chemical recycling, such as solvolysis, pyrolysis and similar thermal decomposition processes, with partial recovering of reinforcing fibres; and (c) mechanical recycling, involving breaking-down of the composite by shredding, milling, comminution or other similar mechanical processes, with size reduction to fibrous and/or powdered products that can be incorporated either as reinforcement or filler into new composite materials. A complete review of current recycling technologies for thermoset composites can be found in Pickering (2006) and Pimenta and Pinho (2011).

Incineration of FRP scrap with energy recovery is listed as recycling method in some literature, but this feature is still up for debate. Incineration does recover part of the energy of the scrap materials whereas landfilling does not; however, air pollution resulting from incineration is a drawback of this method. On the other hand, the fibre and filler content of the materials still end up as landfilled waste, potentially becoming hazardous waste depending on chemical analysis of the ash (Bartholomew, 2004). Because most of FRP products have a low resin-to-fibre ratio, the energy recovery probably doesn't justify the risks associated to this option.

Thermochemical recycling processes, with fibre recovering, have been proposed mostly for carbon and aramid FRP composites (CFRP and AFRP) due to the inherent economic value of reinforcement fibres; whereas for GFRP based products, mechanical recycling has been considered a more viable recycling method. This last method has several important advantages over the previous ones such as the absence of atmospheric pollution by gas emission, much simpler equipment is required as compared with ovens necessary for thermal recycling processes, and it does not require the use of chemical solvents with subsequent environmental impacts. Ensuring that feasible market outlets exist, mechanical recycling is so far considered the favoured recovering technique, at least for relative low cost and clean GFRP waste materials (Palmer et al., 2009; Pickering, 2006). However, mechanically recycled GFRP wastes have not been yet reflected in industry market mainly due to a lack of cost-effective end-use applications for the recyclates, and clearly developed recycling routes (logistics, infrastructures and recycling facilities) between waste producers and potential consumers for the recyclates (Conroy et al., 2006; Palmer et al., 2009; Pickering, 2006). Higher value end markets need to be identified for the recyclates.

In the last years, several attempts have been made in order to overcome this issue by developing feasible end-use applications for the GFRP recyclates. Filler or reinforcement material for artificial wood (Demura et al., 1995), high density polyethylene plastic lumber (George and Dillman, 2000), wood particle board (Conroy et al., 2006), rubber pavements blocks (Itoh and Kaneko, 2002), cement based concrete materials (Asokan et al., 2009, 2010; Correia et al., 2011; Kojima and Furukawa, 1995; Osmani and Pappu, 2010; Tittarelli and Moriconi, 2010; Wakasuhi and Sugiura, 1995; Yamada k Mihashi, 1995), bulk and sheet moulding compounds (DeRosa et al., 2005a, 2005b; Jutte and Graham, 1991) and core material for textile sandwich structures (Adolphs and Branca, 2001), were some of the foreseen potential applications for the recyclates. Most of them have failed at an industrial scale due to one or both of the following reasons: (a) tendency of recyclate addition to negatively affect the mechanical properties of final composite; and (b) negative cost balance, where recycling and refining operation costs outweighed the market value of the virgin products (calcium carbonate and glass fibres); (Halliwell, 2006; Palmer et al., 2009; Pickering, 2006).

Previous studies recently carried out by the present research group (Ribeiro et al., 2011) have highlighted the high potential of mechanically recycled GFRP wastes, generated by the GFRP pultrusion industry, as reinforcement and partial substitutes of fine aggregates on polymer concrete (PC) materials.

PC is a concrete-like material, also called resin concrete, in which a thermoset polymer, usually an unsaturated polyester or an epoxy resin, entirely replaces the cement paste binder. High strength to weight ratio, fast curing time, very low permeability, enhanced impact and damping behaviour and high resistance to chemical, weathering agents and frost attack are some of the enhanced properties of this class of materials over conventional cement based concretes (Fowler, 1999; Ribeiro et al., 2002, 2004, 2009). As drawbacks, the relative high cost, the high sensitivity to creep and to elevated temperatures, the deficient behaviour under fire and the relative high coefficient of thermal expansion and shrinkage have been reported (Fowler, 1999; Marín et al., 2003; Ribeiro et al., 2003a, 2004; Silva et al., 2007; Tavares et al., 2002). Nevertheless, currently, one of the main assets of PC materials is their great ability for incorporating recycled wastes, mainly due to the hermetic nature of the resin matrix (Bignozzi et al., 2000; Garbacz and Sokolowska, 2013; Nóvoa et al., 2004). The use of wastes or byproducts into PCs also leads to both a global reduction cost of final product, which is one of the main drawbacks of these materials over conventional concretes (Garbacz and Sokolowska, 2013), and a less depletion of natural resources.

Outcomes of the previous research on GFRP waste admixed PMs were very promising and demand for further research in this field, 
endorsing the present study. Compared to related end-use applications in cementitious based concrete materials, which have been investigated over the last decade and already reported in several studies (as mentioned before), the proposed solution overcomes some of the problems found, namely: (a) the possible incompatibilities arisen from alkalis-silica reaction (depending upon glass fibre nature); (b) the decrease in the mechanical properties due to high water-cement ratio required to achieve the desirable workability, and (c) the weak adhesion at recyclate-binder interface. Some of the common problems found in the design process of composite materials modified with recycled plastics arise from the lack of bond between the resin matrix and the recyclates (Wong et al., 2012). This weakness, previously reported in several research studies focused on the feasibility of GFRP waste incorporation into new composite materials (DeRosa et al., 2005a; Jutte and Graham, 1991; Rikards et al., 1994), was also detected in the previous experiments of Ribeiro et al. (2011). In order to prevent this undesirable feature, the effect of the incorporation of a silane based adhesion promoter was also investigated and considered as a material factor. It is also expected that the incorporation of the coupling agent will also have an important role on the workability and homogeneity of the final mixtures since it tends to reduce the viscosity of the mixture, promotes a better dispersion of filler fraction and improves wet-out of overall aggregates in the resin binder as reported by Chmielewska et al. (2006) and Czarnecki and Chmielewka (2003).

\section{Experimental programme}

\section{Raw materials and characterization}

GFRP waste material was obtained from the shredding of the leftovers resultant from the cutting and assembly processes of GFRP pultrusion profiles during building sites and it was supplied by Alto, Perfis Pultrudidos Lda., a pultrusion manufacturing company with headquarters in Maia (Portugal). Currently, these leftovers, as well as non-conform profiles and scrap resulting from pultrusion manufacturing process, are landfilled with an estimated cost for the company of $100 \mathrm{D}$ per tonne, which includes landfill tax, transportation and chemical analyses to GFRP wastes. GFRP waste material was comprised essentially of an unsaturated polyester resin (Aropol ${ }^{\circledR}$ FS3992) loaded with calcium carbonate and reinforced with E-glass roving (4800 Tex), continuous filament mat (25 Tex) and surfacing veils.

Shredded GFRP waste was further processed by milling using a Cutting Mill laboratory unit (Retsch SM2000). Two size grades of milled GFRP waste were obtained using bottom sieves inside the grinding chamber with differently-sized meshes. Obtained recycled products, hereinafter designated by coarse $(\mathrm{CW})$ and fine (FW) pultrusion waste, consist of a mix of powdered and fibrous particulate materials with different quantities of varying length of glass fibres as shown in Fig. 1.

GFRP recyclates were characterized in terms of the organic and inorganic fraction contents and particle size distribution. Burning tests carried out according to Volkswagen AG TL 52342 (2003) on five random samples revealed an average inorganic material content of $71 \%(\mathrm{w} / \mathrm{w})$ corresponding to glass fibres $(55 \%, \mathrm{w} / \mathrm{w})$ and calcium carbonate $(16 \%, \mathrm{w} / \mathrm{w})$, and an average resin content of $29 \%$ $(\mathrm{w} / \mathrm{w})$.

Particle size distribution of both types of recyclates, obtained by sieving and laser diffraction techniques (Fig. 2), revealed an average diameter of $390 \mu \mathrm{m}$ or $950 \mu \mathrm{m}$, and a fineness modulus of 1.64 or 2.69 for FW or CW admixtures, respectively. It is worthwhile to point out that both grades of recyclates have the same proportion of glass fibre, calcium carbonate and organic resin and only differ with regard to average particle size (powdered fraction) and average fibre length (fibrous fraction).

Siliceousfoundry sand (SP55, SibelcoLda), with a ratheruniform particle size, an average diameter of $245 \mu \mathrm{m}$ and a fineness modulus of 3.04, was used as fine aggregate. Particle size distribution of foundry sand is also displayed in Fig. 2.

Commercially available unsaturated polyester resin $\left(\right.$ Aropol $^{\circledR}$ FS3992), with a styrene content of $42 \%$, was used as binder. This polymer binder is a rigid, high reactivity and low viscosity resin generally used in pultrusion processes, though it can also be used in bulk and sheet moulding compound applications. The resin system is the same applied as matrix in the manufacturing process of GFRP
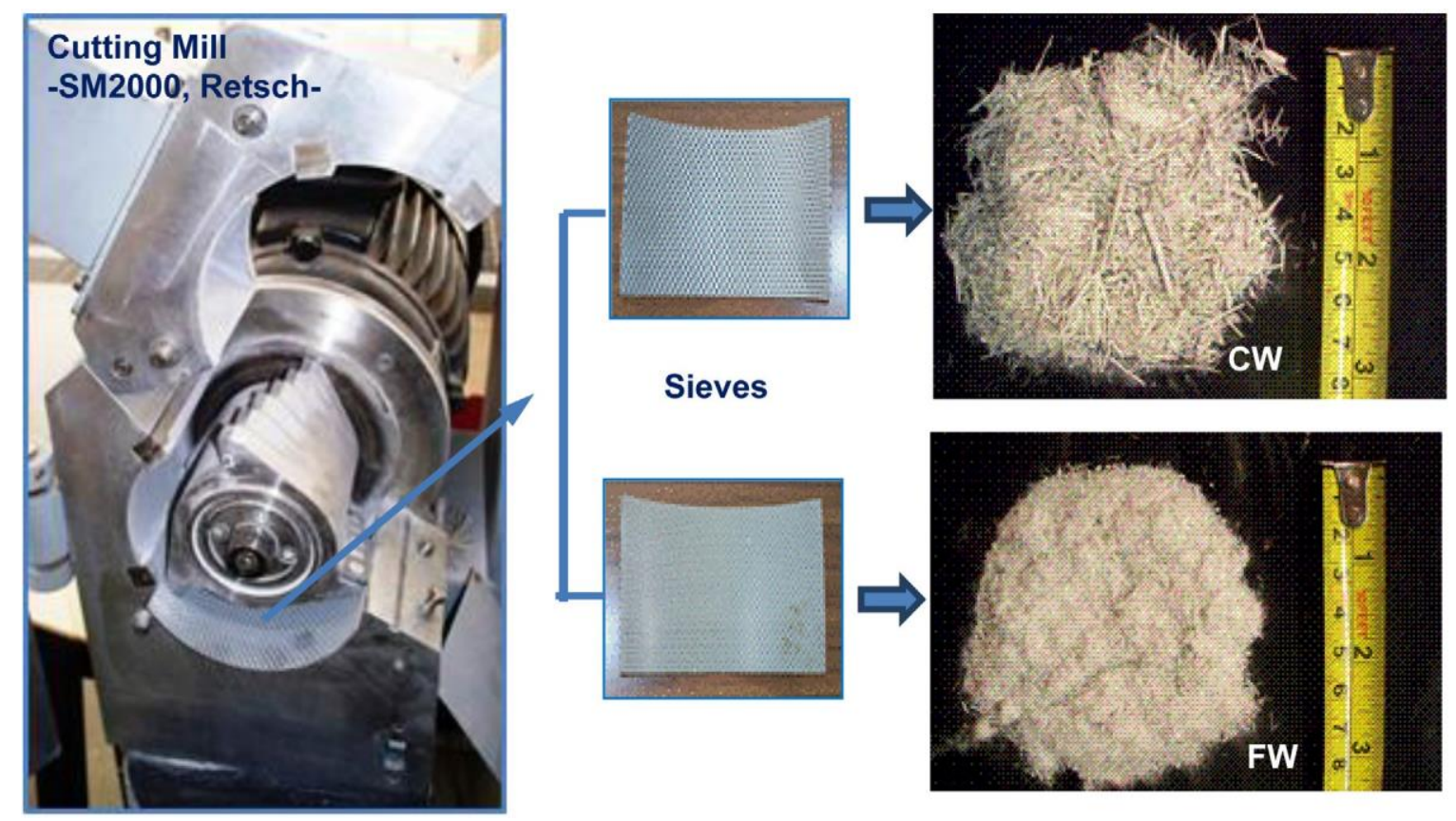

Fig. 1. Cutting Mill laboratory unit used in the grinding and milling processes of GFRP wastes, and the obtained recyclates (CW and FW) according to the bottom sieves applied in the grinding chamber. 


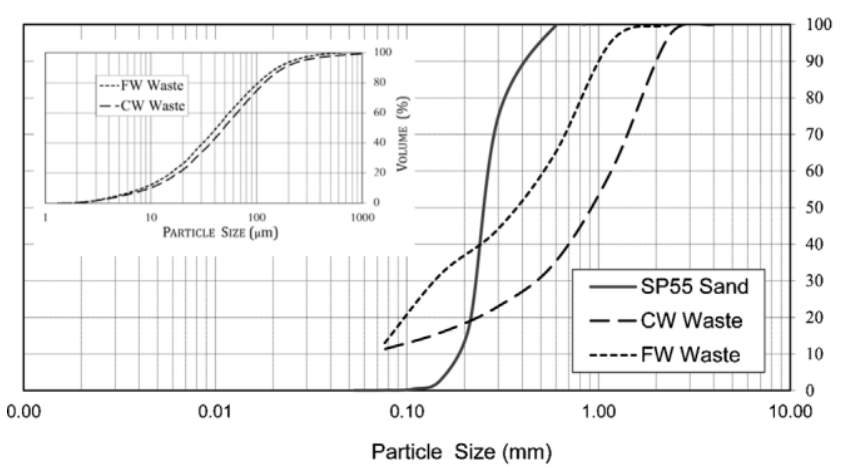

Fig. 2. Particle size distributions of sand aggregates and GFRP waste recyclates obtained by sieving (main figure) and laser diffraction techniques (embedded figure).

pultrusion profiles produced by Alto. Its application in this study as binder matrix was justified in order to prevent possible incompatibility problems with GFRP waste admixtures. The polymerization process of resin system was induced by cobalt octoate ( $0.5 \mathrm{phr})$, as promoter, and $50 \%$ methyl ethyl ketone peroxide solution ( $2 \mathrm{phr})$, as initiator. Physical and mechanical properties of the resin binder, as supplied by the manufacturer, are presented in Table 1 .

An organofunctional silane chemical solution (Dow Corning ${ }^{\circledR}$ Z-6032), with $40 \%$ of active silane in methanol, was applied as adhesion promoter of resin binder to the inorganic aggregates and GFRP recyclates. Z-6032 silane contains a vinylbenzyl and amine organic groups and a trimethoxysilyl inorganic group. As a coupling agent, it can be used either as an additive to a polymer or as a pre-treatment on inorganic surfaces. In this study, Z-6032 silane solution was applied as an additive to the polyester resin binder, in the proportion of $1 \%$ of active silane by weight of resin content.

\section{Mix design, casting process and testing procedures}

The mix design of the reference PM formulation was in accordance with previous studies carried out by Ribeiro et al. (2003b), in which a polyester resin binder with similar viscosity was applied. With a basis on the reference PM formulation, different PM formulations were prepared by mixing the resin binder, with and without silane coupling agent additive, with different sand aggregates/GFRP waste ratios. Analyzed trial formulations correspond to a threefactor mix-level full factorial design, in which 'waste type', 'waste content' and 'silane content' were considered as factors and each onewas run, respectively, at two (CW and FW grades), four $(0 \%, 4 \%$, $8 \%$ and $12 \%$ in weight of total mass) and two $(0 \%$ and $1 \%$ in weight of resin mass) variation levels. Taking into account the number of factors and their variation levels, the number of trial formulations gave by the full factorial design (i.e., all possible combinations between factors' levels) is quite reasonable in terms of experimental programme and not excessively time-consuming. Hence, there was no need to apply other less time-consuming experimental designs in order to reduce the experimental programme.

Theresin to total aggregate(sand plusGFRPadmixtures) weight ratio was kept constant at 1:4 in all formulations; therefore, the

Table 1

Physical and mechanical properties of cured resin (Aropol FS3992).

\begin{tabular}{llc}
\hline Resin properties & Method & Value \\
\hline Heat deflection temperature $\left({ }^{\circ} \mathrm{C}\right)$ & ASTM D-648 & 95 \\
Barkoll hardness & ASTM D-2583 & 45 \\
Tensile strength $(\mathrm{MPa})$ & ASTM D-638 & 60 \\
Flexural strength $(\mathrm{MPa})$ & ASTM D-790 & 110 \\
Elongation at break $(\%)$ & ASTM D-638 & 3.2 \\
\hline
\end{tabular}

Table 2

Mix design of trial formulations.

\begin{tabular}{llclll}
$\begin{array}{l}\text { Trial } \\
\text { formulations }\end{array}$ & $\begin{array}{l}\text { GFRP } \\
\text { waste } \\
\text { type }\end{array}$ & $\begin{array}{l}\text { GFRP } \\
\text { waste } \\
\text { content }^{\mathrm{a}}\end{array}$ & $\begin{array}{l}\text { Silane } \\
\text { content }^{\mathrm{b}}\end{array}$ & $\begin{array}{l}\text { Sand } \\
\text { content }^{\mathrm{a}}\end{array}$ & $\begin{array}{l}\text { Resin } \\
\text { content }^{\mathrm{a}}\end{array}$ \\
\hline FW0 & FW & $0 \%$ & $0 \%$ & $80 \%$ & $20 \%$ \\
FW4 & FW & $4 \%$ & $0 \%$ & $76 \%$ & $20 \%$ \\
FW8 & FW & $8 \%$ & $0 \%$ & $72 \%$ & $20 \%$ \\
FW12 & FW & $12 \%$ & $0 \%$ & $68 \%$ & $20 \%$ \\
CW0 & CW & $0 \%$ & $0 \%$ & $80 \%$ & $20 \%$ \\
CW4 & CW & $4 \%$ & $0 \%$ & $76 \%$ & $20 \%$ \\
CW8 & CW & $8 \%$ & $0 \%$ & $72 \%$ & $20 \%$ \\
CW12 & CW & $12 \%$ & $0 \%$ & $68 \%$ & $20 \%$ \\
FWS0 & FW & $0 \%$ & $1 \%$ & $80 \%$ & $20 \%$ \\
FWS4 & FW & $4 \%$ & $1 \%$ & $76 \%$ & $20 \%$ \\
FWS8 & FW & $8 \%$ & $1 \%$ & $72 \%$ & $20 \%$ \\
FWS12 & FW & $12 \%$ & $1 \%$ & $68 \%$ & $20 \%$ \\
CWS0 & CW & $0 \%$ & $1 \%$ & $80 \%$ & $20 \%$ \\
CWS4 & CW & $4 \%$ & $1 \%$ & $76 \%$ & $20 \%$ \\
CWS8 & CW & $8 \%$ & $1 \%$ & $72 \%$ & $20 \%$ \\
CWS12 & CW & $12 \%$ & $1 \%$ & $68 \%$ & $20 \%$ \\
\hline
\end{tabular}

a Weight content of total mass.

${ }^{\mathrm{b}}$ Weight content of resin mass.

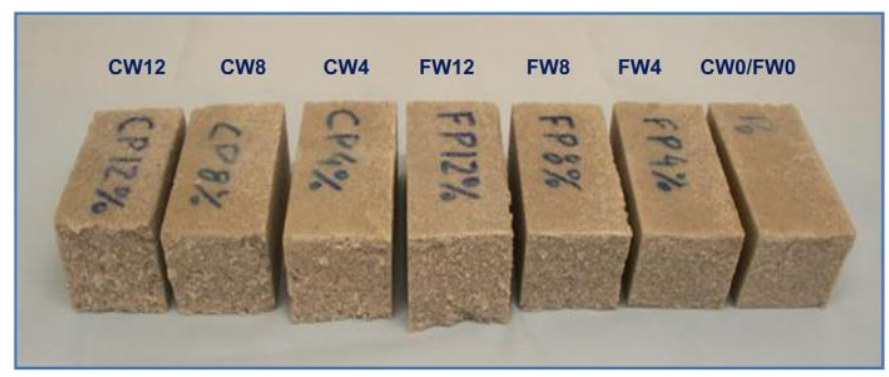

Fig. 3. Samples of broken PM test specimens after being tested in flexural (one sample of each CW and FW test series).

GFRP recyclates played the role of sand aggregate replacement. Resultant mix design formulations, presented in Table 2, were evaluated on the basis of four specimens and the following notation was adopted: CW or FW accounts for the type/grade of GFRP recyclate, the sequent number for the weight content of waste admixture and, when applied, the additional letter ' $S$ ' denotes that the resin binder was modified with $1 \%$ of active silane coupling agent. PM mixtures were prepared in an automatic mixer and casted into standard prismatic moulds $(40 \mathrm{~mm} \times 40 \mathrm{~mm} \times 160 \mathrm{~mm})$ as per RILEM CPT PC-2, 1995. After hardening process $\left(24 \mathrm{~h}\right.$ at $\left.30{ }^{\circ} \mathrm{C} / 50 \% \mathrm{RH}\right)$ the moulds were stripped off and all the test specimens were further cured for $3 \mathrm{~h}$ at $80{ }^{\circ} \mathrm{C}$ before being tested in flexure and compression at the same age, after a minimum conditioning period of $24 \mathrm{~h}$ at room temperature.

Prismatic PM specimens were tested in three-point bending up to failure at the loading rate of $1 \mathrm{~mm} \mathrm{~min}^{-1}$, over a span length of $100 \mathrm{~mm}$, as specified by RILEM CPT PCM-8, 1995. One of the two leftover parts of each broken specimen in bending (as illustrated in Fig. 3) was tested afterwards in compression at the loading rate of $1.25 \mathrm{~mm} \mathrm{~min}^{-1}$, in compliance with UNE 83821, 1992.

\section{Statistical analysis}

Mechanical test results were statistically analyzed for each target response (flexural and compression strengths), using the Matlab 7.6.0 (R2008a) software. Analyses of variance were performed according to $2^{2} 4^{1}$ full factorial design of experiments. The mix-level $2^{2} 4^{1}$ full factorial leads to 16 different trial formulations; however, both pairs of the formulations CW0/FW0 and CWS0/FWS0 have the same composition (i.e., $\mathrm{CWO}=\mathrm{FWO}$ and $\mathrm{CWSO}=\mathrm{FWS} 0$ ). 
Therefore, in this study and for data treatment purposes, these mix design formulations with equal composition share the same specimens and data results.

Parametric analyses of variance (ANOVA) were considered in a first approach. However, the analyses of residues performed according to Shapiro-Wilk's and Levene's tests showed that the ANOVA's assumptions related to the normality and homoscedasticity were not met (Lix et al., 1996; Shapiro and Wilk, 1965). Hence, the Kruskal-Wallis nonparametric analyses of variance were applied to test the null hypothesis (i.e., to verify if each factor has a significant influence on flexural and compressive strength responses, to determine the main contributions of each factor to global variance, and to identify eventual interaction effects across them). A data rank transformation was made considering the entire set of observations from smallest to largest, and the usual parametric procedure was then applied to the ranks of the data instead of to the data themselves as explained in Conover and Rank, 1981. Factors effects with a significance level of $5 \%$ or lower ( $p$-value 0.05 ) were considered statistically significant.

\section{Results}

\section{Compressive test results and statistical analysis}

Fig. 4 summarizes compressive test results obtained for all trial formulations and helps in the data description by resuming both the central tendency and the dispersion measures.

As shown in Fig. 4, average compressive strengths achieved in al trial formulations modified with GFRP waste admixtures are enhanced when compared to those obtained for reference formulations (FW0/CW0 and FWS0/CWSO). A single exception was found for FWS test series in which a decrease of $5 \%$ of compressive strength occurs for $12 \%$ in weight of FW admixture when compared to control formulation (FWS0). In general, compressive strength improvement is more expressive for trial formulations with $8 \%$ in weight of GFRP recyclates, regardless the GFRP waste type and silane coupling agent addition. Obtained outcomes also show that CW based formulations present, in general, a more improved compressivebehaviour than that of homologousformulationsmodified with FW recyclates.
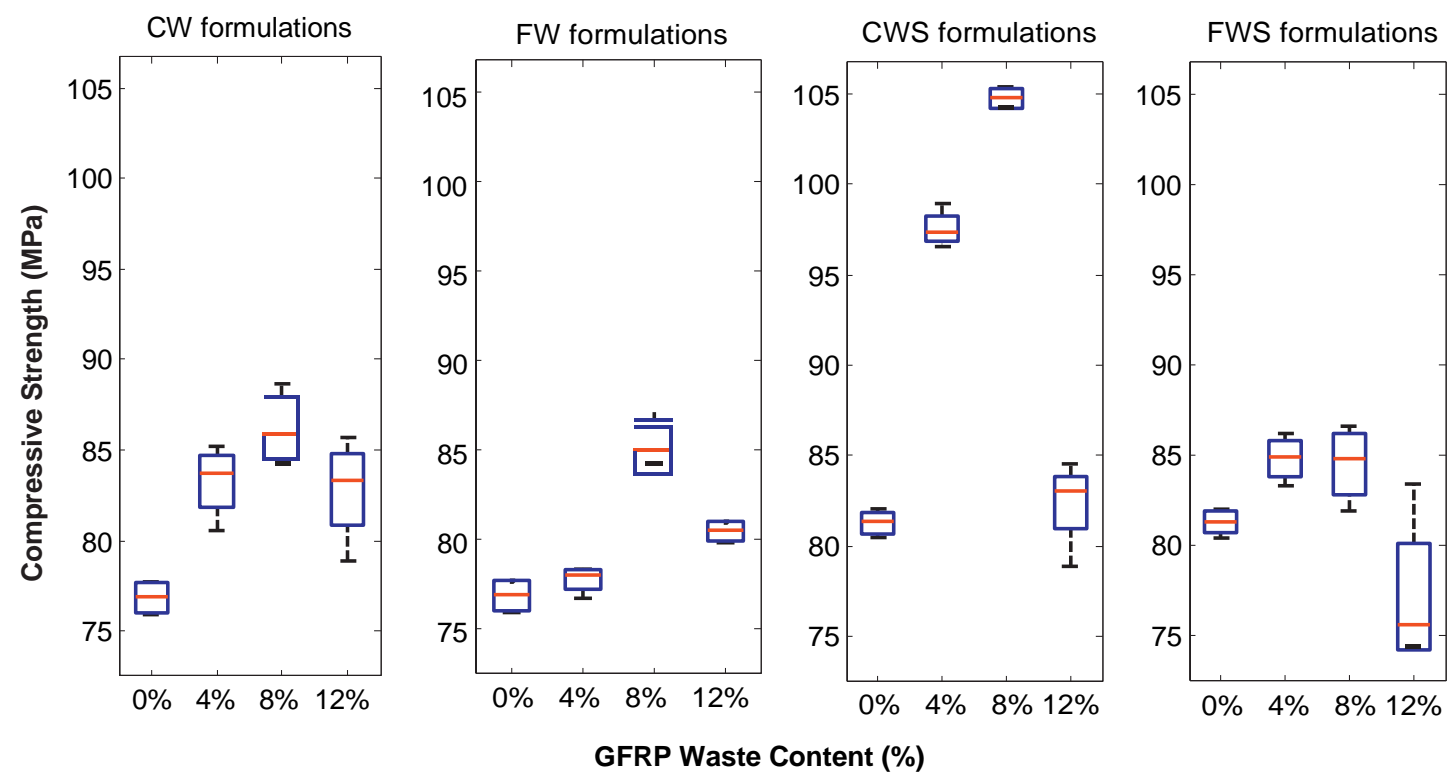

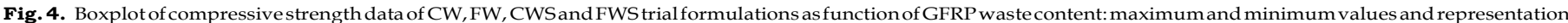
of the lower, the median, and the upper quartiles.
Basic descriptors are supported by the results of the nonparametric three-way ANOVA with ranks transformation presented in Table 3.

From the results provided by the ANOVA, it is clear that all the 3 factors have a significant influence on compressive strength response at the significance level of $5 \%$ ( $p$-values 0.00005$)$. The null hypotheses were also rejected for both 2-factor interactions with 'waste content', denoting the significant influence of these interactions on the target response.

Three-way ANOVA results alsoallowed theidentification of the most influential factor on the compressive strength response as 'waste content', followed with minor relevance by 'waste type' and 'silane content'. The respective percent contributions to the global variation $(\mathrm{P})$, computed as the ratio of the pure sum of squares of the factor to the total sum of squares, as expressed by Eq. (1), are

$P_{X}(\%)=\frac{\mathrm{SS}_{X}-\mathrm{MS}_{E} \cdot \mathrm{df}_{X}}{\mathrm{SS}_{T}} \times 100$

where $P_{X}$ is the percent contribution or relative influence of the factor (or interaction) on the global variance observed; $\mathrm{SS}_{X}$ and $\mathrm{df}_{X}$ are the sum of squares and degrees of freedom of the factor (or interaction), respectively; $\mathrm{MS}_{E}$ is the mean sum of squares associated to the error; and $\mathrm{SS}_{T}$ is the total sum of squares.

The 2-factor interactions 'waste content $\times$ silane content' and

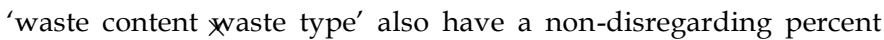
contribution to the global variation of the compressive strength of $10.9 \%$ and $3.0 \%$, respectively.

\section{Flexural test results and statistical analysis}

Boxplots of Fig. 5 summarize the flexural test results obtained for all trial formulations.

In general, GFRP waste modified PMs demonstrated an improved flexural behaviour over reference trial formulations. The same trend was already been observed for compressive strength response. However, increases in flexural strength were not as outstanding as those that occurred for compressive strength, especially for the test series without silane addition. Also, in FWS test series, a larger decay on flexural strength (12\%) was observed for FWS12 trial formulation over control formulation(FWS0). Different trends $46.8 \%, 10.1 \%$ and $8.5 \%$, respectively. 
Table 3

Kruskal-Wallis ANOVA test results for compressive strength response.

\begin{tabular}{|c|c|c|c|c|c|}
\hline Source & Sum sq. & $\mathrm{df}$ & Mean sq. & Chi-sq & $p$-value \\
\hline Waste content & $10,426.5$ & 3 & 3475.5 & 49.9 & $\leq 0.00005$ \\
\hline Waste type & 2280.1 & 1 & 2280.1 & 32.7 & $\leq 0.00005$ \\
\hline Silane content & 1936.0 & 1 & 1936.0 & 27.8 & $\leq 0.00005$ \\
\hline ‘Waste content $\times$ waste type' & 867.2 & 3 & 289.1 & 4.2 & 0.0108 \\
\hline 'Waste content $\times$ silane content' & 2583.5 & 3 & 861.2 & 12.4 & $\leq 0.00005$ \\
\hline ‘Waste type $\times$ silane content' & 39.1 & 1 & 39.1 & 0.6 & 0.4576 \\
\hline 'Waste content $\times$ waste type $\times$ silane content' & 360.2 & 3 & 120.1 & 1.7 & 0.1747 \\
\hline Error & 3343.5 & 48 & 69.7 & & \\
\hline Total & $21,836.0$ & 63 & & & \\
\hline
\end{tabular}
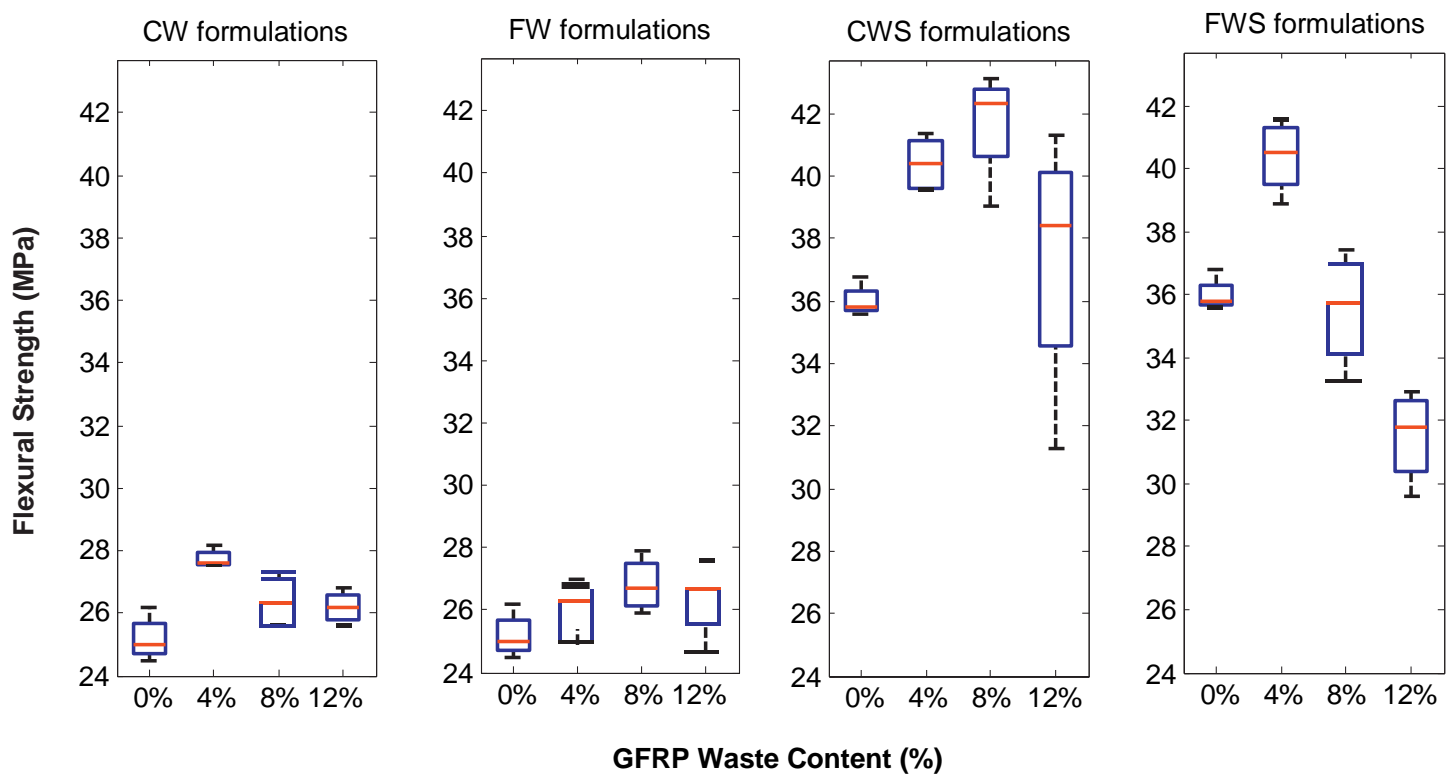

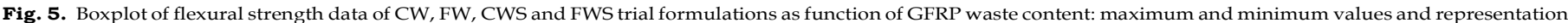
of the lower, the median, and the upper quartiles.

Table 4

Kruskal-Wallis ANOVA test results for flexural strength response.

\begin{tabular}{|c|c|c|c|c|c|}
\hline Source & Sum sq. & df & Mean sq. & Chi-sq & $p$-value \\
\hline Wastecontent & 1845.1 & 3 & 615.0 & 15.9 & $\leq 0.00005$ \\
\hline Waste type & 400.0 & 1 & 400.0 & 10.4 & 0.0023 \\
\hline Silanecontent & $16,384.0$ & 1 & $16,384.0$ & 424.1 & $\leq 0.00005$ \\
\hline ‘Waste content $\times$ waste type' & 136.6 & 3 & 45.5 & 1.2 & 0.3277 \\
\hline 'Waste content $\times$ silane content' & 266.1 & 3 & 88.7 & 2.3 & 0.0895 \\
\hline ‘Waste type $\times$ silane content' & 132.2 & 1 & 132.2 & 3.4 & 0.0705 \\
\hline 'Waste content $\times$ waste type $\times$ silane content' & 817.4 & 3 & 272.5 & 7.0 & 0.0005 \\
\hline Error & 1854.5 & 48 & 38.6 & & \\
\hline Total & $21,836.0$ & 63 & & & \\
\hline
\end{tabular}

were also found for the effect of GFRP waste content on flexural strength response according to recyclate grade (CW or $\mathrm{FW}$ ) and silane content addition. ANOVA outputs for flexural strength response, displayed in Table 4, allow for a more in depth analysis of obtained results.

According to the nonparametric ANOVA test results the null hypothesis is rejected for all of the three main factors, thus indicating that all of them have a significant statistical influence on flexural strength. Among the three factors, 'silane content' is clearly the most influential parameter on flexural strength response, contributing with almost $75 \%$ to global variation, followed by 'waste content' with $7.5 \%$ influence, and finally' waste type' with a modest contribution of $1.5 \%$ (percent contributions computed per Eq. (1).

Regarding the interaction effects, for a confidence level of $95 \%$, no evidences were found that the 2 -factor interactions have any significant influence on flexural strength response; however, the null hypothesis was not rejected for the 3 -factor interaction ( $p$ value $=0.0005)$ that contributes with $2.8 \%$ to global variation. Though, caution should be taken when analysing the interaction effects results obtained by Kruskal-Wallis test as this analysis may be unable to identify interaction effects when multiple factors are involved (Wobbrock et al., 2011).

\section{Discussion}

In order to get a better understanding of the effects of material factors on the mechanical strengths of PMs, the response graphs of the main effects of each factor, as well as the interaction effects across them, are plotted in Figs. 6 and 7, respectively. So as to 
a) Waste Content - Main Effect

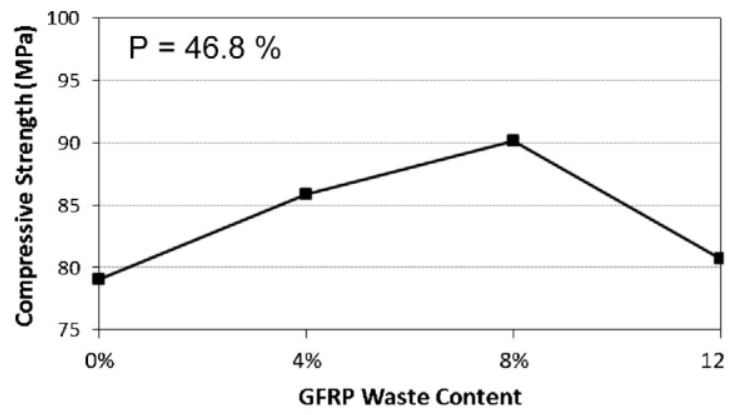

b)

Waste Type - Main Effect

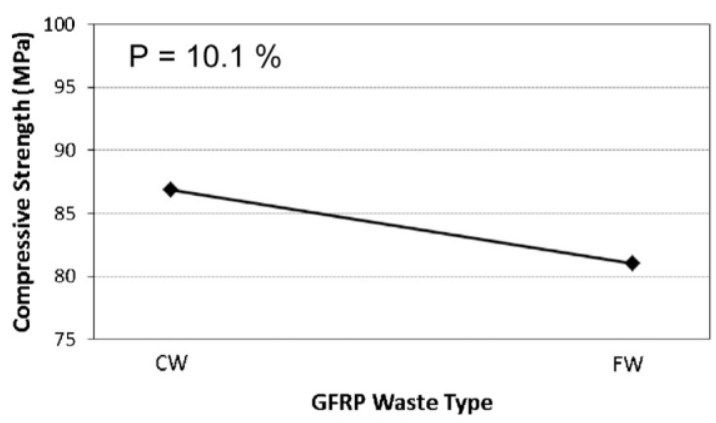

c)

Silane Content - Main Effect

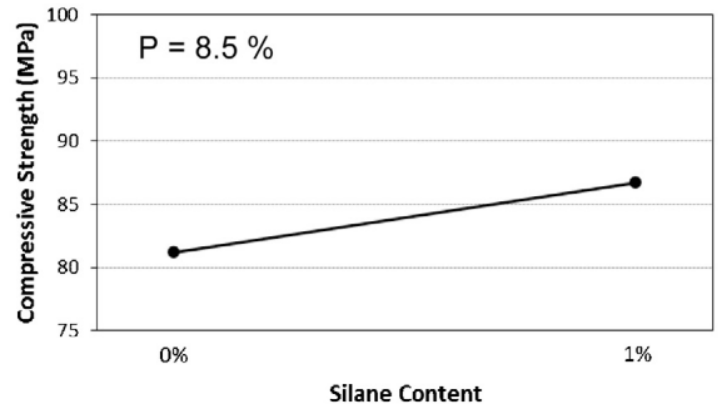

Waste Content - Main Effect

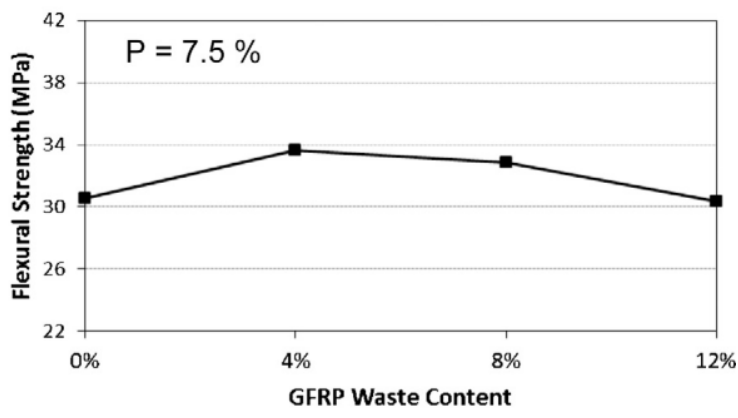

Waste Type - Main Effect

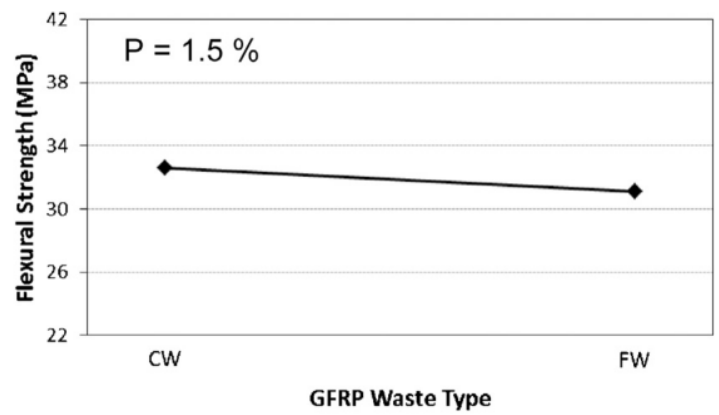

Silane Content - Main Effect

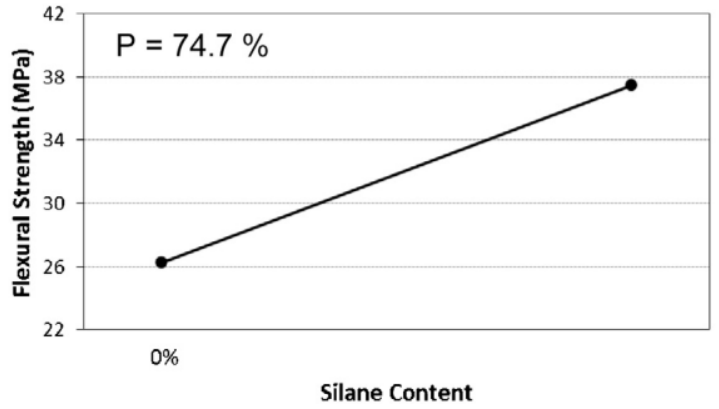

Fig. 6. Response graphs of the main effects of 'waste content' (a), 'waste type' (b) and 'silane content' (c) on compressive and flexural strength responses and respective contributions to global variation $(\mathrm{P} \%)$.

emphasize the effects, the absolute values were applied in the computation of marginal averages instead of the rank values.

\section{Effect of GFRP waste content}

'GFRP waste content' is the most influential factor on compressive strength response and the second most influential factor on flexural strength response of modified mortars, contributing with $46.8 \%$ and $7.5 \%$, respectively, to global variation. As stressed by the response graphs plotted in Fig. 6a, the partial replacement of sand aggregates by GFRP recyclates, at least for the lowest replacement ratios, has a significant incremental effect on mechanical strengths of modified PMs. However, distinct trendswereobserved for the effect of the waste admixture on mechanical performance, according to both the amount of waste addition and the mechanical response itself (in compression or in flexure).

In compression, loading capacity of PMs increases with increasing replacement amounts of sand aggregates by GFRP recyclates up to $8 \%$ in waste weight content. Overall average compressive strength increases of $8 \%$ and $14 \%$, corresponding to replacement weight ratios of $4 \%$ and $8 \%$, respectively, were observed with regard to waste-free PMs. The almost linear increase in compressive strength with GFRP waste content might be attributed to a more continuous particle size distribution of the mix sand/waste particles. The contribution of powder fraction of GFRP recyclates to filler amount of sand aggregates, which leads to an inferior void volume for dry-packed aggregate, had a relevant role in this feature. Generally, aggregate mixtures with the maximum bulk density lead to higher compressive strengths due to improved aggregate agglomeration. Above $8 \%$ in waste content, decreases in compressive strength occur for all trial formulations compared to PMs modified with less waste contents. Nevertheless, compressive strengths remain higher than those of waste-free formulations (with a single exception for FWS test series). This overall trend was mainly governed by CW and CWS test series (especially by this last one), in which increases in compressive strength with increasing waste content up to $8 \%$, followed by decrease after this point, were very pronounced.

In flexure, a different trend was found for the effect of 'waste content'. As shown in Fig. 6a, the turning point on the trend of the material behaviour of PMs seems to be approximately $4 \%$ in weight of waste content, regardless of the GFRP waste type and the silane 
Waste Content * Waste Type

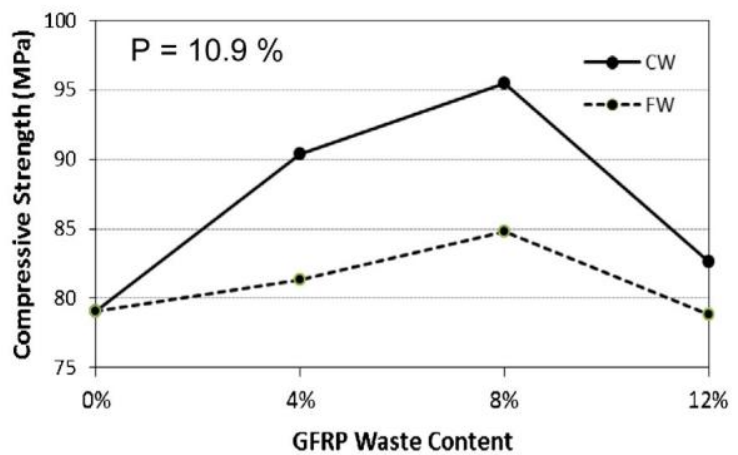

b)

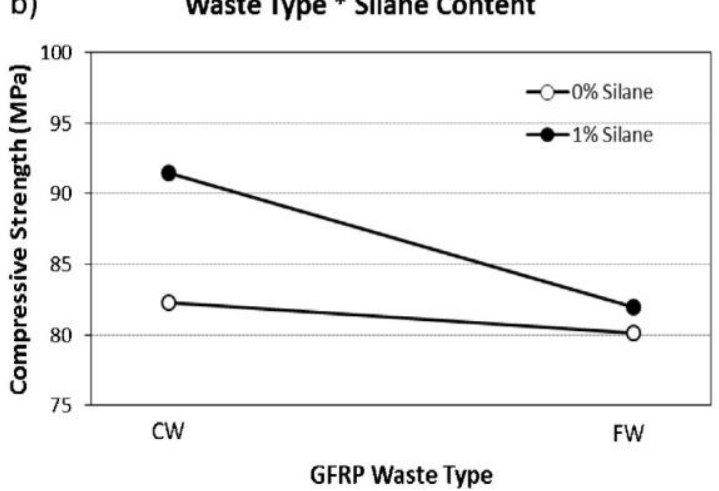

Waste Content * Waste Type

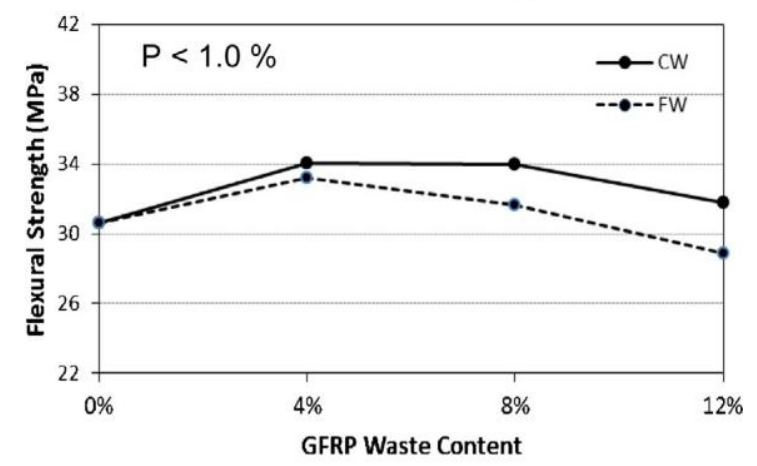

Waste Type * Silane Content

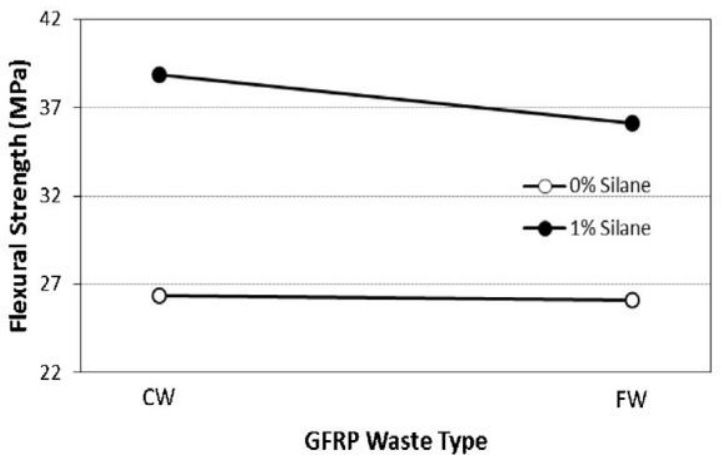

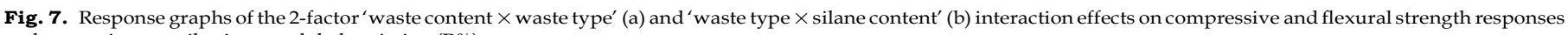
and respective contributions to global variation $(\mathrm{P} \%)$.

content addition. For this amount of sand replacement, an overall average increase of $10 \%$ occurred for GFRP waste modified PMs over waste-freeformulations. However, after this point, progressiveand steady decreases in bending strength were observed compared to $4 \%$-waste admixed formulations. As shown in Fig. 5, both CWS and FWS test series have an important role on this feature taking into account that bending strengths of trial formulations without silane coupling agent are in general hardly affected by GFRP waste amount. It was expected that the fibrous fraction of GFRP recyclates would have a significant reinforcing effect and lead to significant improvements in flexural behaviour. Although this expected flexural improvement did actually occur for CWS test series, in which progressive increases of $12 \%$ and $16 \%$ on bending strength were noticed for CWS4 and CWS8 trial formulations, respectively; strong decrease in flexural strength was observed for FWS test series when FW waste content was increased from $4 \%$ to $8 \%$. This tendency became even more noticeable for further addition amounts of fine waste (FWS12).

As larger amounts of sand were replaced by GFRP waste throughout the test series (from $0 \%$ to $12 \%$ ), the overall specific surface area of aggregates (sand plus recyclates) was progressively increased, while resin content was kept constant at $20 \%$ in weight in all formulations. The higher specific surface area of GFRP waste particles when compared to sand particles, especially in the case of FW admixture, which requires higher contents of binder matrix for a proper wetting and cohesive bonding, is for certain the main reason for the observed inflexion points in the trend of the behaviour of the materials (around $8 \%$ in waste content for compression and $4 \%$ for flexure). Poor workability and deficient wetting of overall aggregates in cementitious concrete materials with increasing contents of FRP recyclates was also reported by Correia et al. (2011) and Ogi et al. (2005). However, whereas in cementitious concrete mixtures the fine-tuning of the water/cement ratio may overcome this undesirable feature (but with an eventual decrease in final mechanical properties), in polymer concrete mixtures, higher binder contents are needed to improve wetting and workability, which leads to significant cost increases in the final product.

\section{Effect of GFRP waste type}

'GFRP waste type' factor has a relatively significant effect on compressive strength and a minor influence on flexural strength response of modified PMs, contributing with $10.1 \%$ and $1.5 \%$ respectively, to global variation. As shown in the response graphs of Fig. 6b, PMs modified with $\mathrm{CW}$ present improved mechanical behaviour over FW admixed mortars. This feature, also highlighted in Fig. $7 \mathrm{a}$ and $\mathrm{b}$, is more pronounced regarding compressive than flexural behaviour. Considering the global response of mechanical strength, the addition of $\mathrm{CW}$ recyclates leads to higher increases in loading capacities than homologous amounts of FW admixtures. For $4 \%, 8 \%$ and $12 \%$ contents of GFRP waste addition, increases of $12.6 \%, 15.3 \%$ and $4.2 \%$, respectively, on average variation of mechanical properties of $\mathrm{CW}$ admixed formulations were found, against increases of $5.3 \%, 5.0 \%$ and $0.1 \%$ on homologous values of $\mathrm{FW}$ modified formulations. The poorer response of FW admixed mortars to increasing amounts of GFRP waste might be explained, once again, by the distinct specific surface areas and geometric characteristics between $\mathrm{CW}$ and FW recyclates. FW admixtures, with finer particles, conduct to 'drier' mixes and would require higher contents of resin binder to attain the same level of wetting, which justify the drop off in mechanical properties for sand replacement ratios higher than $4 \%$.

On the other hand, $\mathrm{CW}$ recyclates present a wide range of fibre lengths varying between $25 \mathrm{~mm}$ and a few micrometres, whereas 
the maximum fibre length of FW is around $5 \mathrm{~mm}$. Therefore, $\mathrm{CW}$ has a higher reinforcing effect than FW. This feature generally leads to improved mechanical behaviour of host material providing that good interface bonding is ensured. In general terms, taking into account the distinct geometric characteristics of FW and $\mathrm{CW}$ recyclates, it can be stated that whereas FW acts more like a filler extension for sand aggregates of modified mortar and lead to a less void-volume of resultant material; CW acts mainly as reinforcing material, as indicated by its improved mechanical strength and observed less brittle behaviour of modified mortars.

The obtained results highlight the importance of sieving and sorting operations during and after the recycling process of the FRP wastes. Relevant properties of the recyclates that will affect the performance of the final composite are dictated by these key operations. This feature is also stressed in Rikards et al. (1994) and Palmer et al. (2009), some of the few thorough investigations that take into consideration fibre and filler fractions, various combinations of recyclate grades and replacement percentages. With a well-designed combination of powder and fibre fractions, better properties on the final composites could be achieved due to a better packing of overall aggregate system, without compromising both workability and wettability of the mixture.

Finally, a last point must be stressed, since no real differences exist between the pairs of sets CW0/FW0 and CWS0/FWS0 (they share, in fact, the same replicates), the effect of 'waste type' on global variance of target responses (as well as the interaction effect of this factor with the other factors), may have somehow been concealed.

\section{Effect of silane content}

As already expected, the incorporation of a silane coupling agent significantly improved the mechanical strength of PM formulations. The effect of the 'silane content' factor is especially remarkable with regard to flexural strength response, contributing with more than $74 \%$ to global variance (Fig. $6 \mathrm{c}$ ). The numeric value of the effect of this material factor on flexural strength response is $11.3 \mathrm{MPa}$, which means that, on average, silane modified PMs present a flexural strength higher in $11.3 \mathrm{MPa}$ over silane-free PMs. The inherent contribution of the silane coupling agent as an adhesion promoter at the interface between the resin matrix and both the sand aggregates and the recyclates, improving the organic-inorganic phase bridge, is clearly the main reason for the observed strong effect of this factor on flexural strength response of PMs.

With regard to the compressive strength response, a minor contribution of 'silane content' to the global variance was observed $(P=8.5 \%)$, in which 'GFRP waste content' prevails as the mostinfluential and significant factor.

Despite the non-rejection of null hypothesis for 'wastetype silane content' interaction regarding both the flexural and compressive strength responses, the incremental effect of the silane coupling agent on the mechanical strength is more noticeable for CW admixed formulations than for trial formulations modified with the finer recyclates, either in flexure or in compression (Fig. $7 \mathrm{~b}$ ). In flexure, the beneficial effect of silane coupling agent is steadier throughout CWS test series than in the case of FWS test series. In compression, for the first levels of waste addition, the increases on strength were also higher for CWS trial formulations than for FWS trial formulations; however, for the highest levels, slight decreases on compressive strength were found either for CWS or for FWS test series when compared to homologous silanefree trial formulations. No feasible explanation was found for the observed behaviour (e.g., at this stage of the study it is not clear why silane coupling agent addition had a detrimental effect on compressive behaviour of FWS8, FWS12 and CWS12 trial formulations). Nevertheless, the high scatter of data results associated to these particular formulations (especially in the case of FWS12) does not allow inferring reliable conclusions on the effect of silane coupling agent addition on compressive behaviour of resultant modified mortars. It is expected that foreseen future studies, with partial replication of experimental programme and microstructure analysis of fracture surface of GFRP waste modified PMs, will help on the clarification of this issue.

\section{Effect of interactions between factors}

As already mentioned in Mix design, casting process and testing procedures, when multiple factors are involved the nonparametric Krushal-Wallis analysis may not be able to identify interaction effects. Though, at least for compressive strength response, it is clear from response graphs plotted in Fig. $7 \mathrm{~b}$ ('waste type silane content' interaction effect) that the adhesion promoter is more efficient for coarse waste than for fine waste. Higher specific surface area of aggregates mix (sand plus GFRP waste), specially with FW, requiring higher contents of resin binder (in which the silane coupling agent is dissolved) is likely the main reason for observed interaction behaviour.

\section{Conclusions}

Experiments were performed in order to determine the effect of GFRP recyclates and silane coupling agent addition on mechanical behaviour of polyester PMs. For the trial formulations analyzed in this study and with basis on the obtained test results the following conclusions may be drawn:

- The partial replacement of sand aggregates by GFRP waste materials has an overall incremental effect on both flexural and compressive strengths of resultant PMs, regardless of the GFRP wastecontent, typeand silanecouplingagentaddition. $4 \%$ and $8 \%$ in GFRP waste content constitute the turning points in the trend of the behaviour of mortar materials for flexural and compressive strength responses, respectively.

- PMs modified with coarse waste (CW) show improved mechanical behaviour over fine waste (FW) based PMs, either in flexural or incompression.

- The observed dissimilar behaviour of trial formulations, according to the mechanical strength response (flexural or compression) and the grade size of GFRP recyclates (CW or FW), can be attributed to intrinsic differences between the geometric characteristics and specific surface areas of FW and CW admixtures; whereas FW acts more like a filler extension for sand aggregates of modified mortars, CW acts mainly as reinforcing material.

- The incorporation of the silane coupling agent significantly improves the mechanical behaviour of PM formulations, especially with regard to flexural strength. The incremental effect of the silane coupling agent on the mechanical strength is more noticeable for $\mathrm{CW}$ admixed formulations than for trial formulations modified with finer recyclates, either in flexure or in compression.

- The best combination of factor's levels that maximize both flexural and compressive strengths of modified PMs is achieved for $8 \%(\mathrm{w} / \mathrm{w})$ of sand replacement by coarse GFRP waste recyclates, and incorporation of $1 \%$ of active silane to resin binder.

The findings of this study highlight a potential cost-effective end-use application for thermoset GFRP waste recyclates, thus opening a door to a new agenda for GFRP scrap materials, notas 
an expensive waste disposal but as a profitable reusable resource in the production of concrete-polymer based products.

\section{Funding}

This work was supported by the 'ADI, Agência de Inovação' [PultrEficaz/5488/005/2010], and the 'FEDER, Fundo Europeu de Desenvolvimento Regional' [HybridPultrusion, QREN co-promoção 21557].

\section{Acknowledgements}

The technical support of 'Alto-Perfis Pultrudidos Lda.' process and the scientific editing of the manuscript by Dr. Antony Danko are gratefully acknowledged.

\section{References}

Adolphs G, Branca A. New approaches in recycling thermoset composites. In: Proceedings Composites 2001 Convention and Trade Show; 2001.

Asokan P, Osmani M, Price ADF. Assessing the recycling potential of glass fibre reinforced plastic waste in concrete and cement composites. J Clean Prod 2009;17:821-9.

Asokan P, Osmani M, Price ADF. Improvement of the mechanical properties of glass fibre reinforced plastic waste powder filled concrete. Constr Build Mater 2010;24:448-60.

Bartholomew K. Fiberglass reinforced plastics recycling, technical report - Minnesota technical assistance program, December; 2004, http://mntap.umn.edu/fiber/resources/report12-04.pdf (August 2013).

Bignozzi MC, Saccani A, Sandrolini F. New polymer mortars containing polymeric wastes. Part 1: Microstructure and mechanical properties. Compos A-ApplSci Manuf 2000;31:97-106.

Broekel J, Scharr G. The specialities of fibre reinforced plastics in terms of product lifecycle management. J Mater Process Tech 2005;162-163:725-9.

Chmielewska B, Czarnecki L, Sustersic J, Zajc A. The influence of silane coupling agents on the polymer mortar. Cement Concrete Comp 2006;28:803-10.

Conover WJ, Rank Iman RL. Transformations as a bridge between parametric and nonparametric statistics. Am Stat 1981;35:124-9.

Conroy A, Halliwell S, Reynolds T. Composite recycling in the construction industry. Compos A-Appl Sci Manuf 2006;37:1216-22.

Correia JR, Almeida NM, Figueira JR. Recycling of FRP composites: reusing fine GFRP in concrete mixtures. J Clean Prod 2011;19:1745-53.

Correia SL, Souza FL, Dienstmann G, Segadães AM. Assessment of the recycling potential of fresh concrete waste using a factorial design of experiments. Waste Manage 2009;29:2886-91.

Correia SL, Partala T, Loch FC, Segadães AM. Factorial design used to model the compressive strength of mortars containing recycled rubber. Compos Struct 2010;92:2047-51.

Czarnecki L, Chmielewka B. Fracture and fractography of silane modified resin mortars. Int J Restor Build Monum 2003;9:603-18

Demura K, Ohama Y, Stoh T. Properties of artificial wood using FRP powder. In: Proceedings International RILEM Workshop: Disposal and Recycling of Organic and Polymeric Construction Materials; 1995

DeRosa R, Telefeyan E, Gaustad G, Mayes S. Strength and microscopic investigation of unsaturated polyester BMC reinforced with SMC recyclate. J Thermoplast Compos 2005a;18:333-49.

DeRosa R, Telefeyan E, Gaustad G, Mayes S. Current State of recycling sheet molding compounds and related materials. J Thermoplast Compos 2005b;18: 219-40.

Fowler DW. Polymer in concrete: a vision for the 21st century. Cement Concrete Comp 1999;21:449-52.

Garbacz A, Sokolowska JJ. Concrete-like polymer composites with fly ashescomparative study. Constr Build Mat 2013;38:689-99.

George S, Dillman S. Recycled fiberglass composite as a reinforcing filler in postconsumer recycled HDPE plastic lumber. In: Proceedings SPE/ANTEC 2000: Annual Technical Conference; 2000.

Halliwell S. End of life options for composite waste: recycle, reuse or dispose? Best practice guide. National composite network; 2006, http://www. tech.plym.ac.uk/sme/mats324/Publications/Halliwell\%20on\% 20composites\%20EOL.pdf (11.4.13).

Itoh T, Kaneko M. Pavement blocks from recycled GRP material. In: Proceedings COMPOSITES 2002 Convention and Trade Show; 2002.

Jutte RB, Graham WD. Recycling SMC. In: Proceedings 46th Annual Conference, Composite Institute, Society of the Plastic Industry; 1991.

Karbhari VM. Use of composite materials in civil infrastructures in Japan. WTEC report. International Technology Research Institute, World Technology (WTEC) Division; 1998.

Kojima A, Furukawa S. Preparation and properties of lightweight high-strength mortars containing FRP fine powder as aggregates. In: Proceedings Int. RILEM
Workshop: Disposal and Recycling of Organic and Polymeric Construction Materials; 1995.

Lix LM, Keselman JC, Keselman HJ. Consequences of assumption violations revisited a quantitative review of alternatives to the one-way analysis of variance $F$-test. Rev Educ Res 1996;66:579-619.

LUCINTEL. Global glass fiber market 2012-2017: trend, forecast, and opportunity analysis. SKU: EC4904124 Lucintel Report, August 2012; 2012.

Marín CG, Santiago MO, Fernandez JR, Garcia MRR. Fire tests on polyester polymer mortas. J Polym Eng 2003;23:353-68.

Marques RC, Cruz NF, Carvalho P. Assessing and exploring (in)efficiency in Portuguese recycling systems using nonparametric methods. Resour Conserv Recy 2012;67:34-43.

Muthukumar M, Mohan D. Optimization of mechanical properties of polymer concrete and mix design recommendation based on design of experiments. J Appl Polym Sci 2004;94:1107-16.

NóvoaPJRO, Ribeiro MCS, Ferreira AJM, Marques AT. Mechanicalcharacterization of lightweight polymer mortars modified with cork granules. Compos Sci Technol 2004;64:2197-205.

Ogi K, Shinoda T, Mizui M. Strength in concrete reinforced with recycled CFRP pieces. Compos A-Appl Sci Manuf 2005;36:893-902.

Osmani M, Pappu A. An assessment of the compressive strength of glass reinforced plastic waste filled concrete for potential applications in construction. Concr Res Lett 2010;1:1-5.

Palmer J, Ghita OR, Savage L, Evans KE. Successful closed-loop recycling of thermoset composites. Compos A-Appl Sci Manuf 2009;40:490-8.

Pickering SJ. Recycling technologies for thermoset composite materials-current status. Compos A-Appl Sci Manuf 2006;37:1206-15.

Pimenta S, Pinho ST. Recycling carbon fibre reinforced polymers for structural applications: Technology review and market outlook. Waste Manage 2011;31:378-92.

Ribeiro MCS, Tavares CML, Ferreira AJM. Chemical resistance of epoxy and polyester polymer concrete to acids and salts. J Polym Eng 2002;22:27-44.

Ribeiro MCS, Reis JML, Ferreira AJM, Marques AT. Thermal expansion of epoxy and polyester polymer mortars plain polymer mortars and fibre reinforced polymer mortars. Polym Test 2003a;22:849-57.

Ribeiro MCS, Tavares CML, Figueiredo M, Fernandes AA, Ferreira AJM. Bending characteristics of resin concretes. Mater Res 2003b;6:247-54.

RibeiroMCS, Nóvoa PR, Ferreira AJM, Marques AT. Flexural performance of polyester and epoxy polymer mortars under severe thermal conditions. Cement Concrete Comp 2004;26:803-9.

Ribeiro MCS, Ferreira AJM, Marques AT. Natural and artificial weathering effects on long-term performance of polymer mortars. Mech Compos Mater 2009;45:515-26.

Ribeiro MCS, Meixedo JP, Fiúza A, Dinis ML, Castro ACM, Silva FJG, et al. Mechanical behaviour analysis of polyester polymer mortars modified with recycled GFRP waste materials. In: Proceedings ICECE 2011, Int. Conference on Environment and Civil Engineering; 2011 (published on World Academy of Science, Engineering and Technology 75365-71).

Rikards R, Goracy K, Bledzki AK, Chate A. Prediction of mechanical properties of composites with recycled particles. Mech Compos Mater 1994;30:563-74.

RILEM CPT PC-2. Method of test for flexural strength and deflection of polymermodified mortars, technical committee CPT-113, RILEM recommendation; 1995

RILEM CPT PCM-8. Method of test for flexural strength and deflection of polymermodified mortars, technical committee CPT-113, RILEM recommendation; 1995

Shapiro SS, Wilk MB. Analysis of variance test for normality (complete samples). Biometrika 1965;52:591-611.

Silva MAG, Silva ZCG, PetrographicSimãoJ. mechanical aspects of accelerated ageing of polymeric mortars. Cement Concrete Comp 2007;29:146-56.

Sims G. UK polymer composites sector: foresight study and competitive analysis. NPL report MAT C(A)80. Middlesex: National Physical Laboratory Materials Center; 2001.

Tavares CML, Ribeiro MCS, Ferreira AJM, Guedes RM. Creep Behaviour of FRPreinforced polymer concrete. Compos Struct 2002;57:47-51.

Tittarelli F, Moriconi G. Use of GFRP industrial by-products in cement based composites. Cement Concrete Comp 2010;32:219-25.

UNE 83821:1992. Morteros Métodos de ensayo; Morteros endurecidos; Determinación de las resistências a flexión y a compressión. Una Norma Española,1992.

Villanueva A, Delgado L, Luo Z, Eder P, Catarino AS, Litten D. Study on the selection of waste streams for end-of-waste assessment. JRC Scientific and Technical Reports, EUR 24362 EN-2010 Final Report, Joint Research Center, 2010.

Volkswagen. AG TL 523 42. GF-UP resin for encapsulations, material requirements. Standards Department of Volkswagen Group Parties; 2003.

Wakasuhi M, Sugiura A. Properties of autoclaved cement paste containing scrap FRP powder. In:Proceedings International RILEM Workshop: Disposal and Recycling of Organic and Polymeric Construction Materials. Tokyo; 1995.

Wobbrock JO, Findlater L, Gergle D, Higgins JJ. The aligned rank transformation for nonparametric factorial analyses using only ANOVA procedures. In: Proceedings ACM Conference on Human Factors in Computing Systems; 2011.

Wong KH, Mohammed DS, Pickering SJ, Brooks R. Effect of coupling agents on reinforcing potential of recycled carbon fibre for polypropylene composite. Compo Sci Technol 2012;72:835-44.

Yamada k Mihashi H. Recycling of FRP as cementitious composite. In: In: Proceedings International RILEM Workshop: Disposal and Recycling of Organic and Polymeric Construction Materials. Tokyo; 1995. 